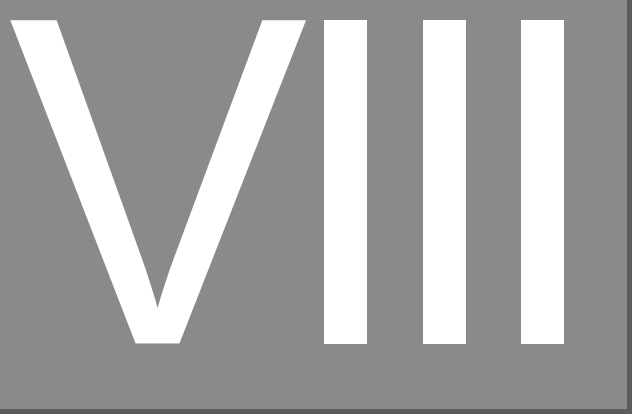

\title{
ENTRE A REALIDADE E O IMAGINÁRIO: A HIPER-REALIDADE E OS PROCESSOS COGNITIVOS
}

\section{Between reality and imagination: The hyperreality and cognitive processes \\ Casa publicadora brasilera, Brasil}

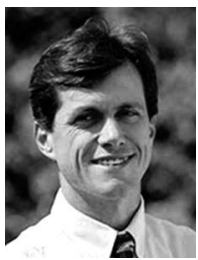

\section{Vanderlei Dorneles}

Doctor en Ciencias por la Universidade de São Paulo, Brasil. Docente del Seminario Adventista Latinoamericano de Teología, SALT. Editor de la revista Hermenéutica bajo la dirección del SALT. Su última investigación fue publicada bajo el título "O Último Império". Ponente nacional e internacional. Actualmente se desempeña como editor de la Casa Publicadora Brasilera. 


\section{Resumen}

Este artículo trata sobre los conceptos de realidad e imaginación en el desarrollo de la tecnología de la comunicación y la virtualidad. A partir de supuestos de la teoría crítica de la cultura de masas y el espectáculo, se analizan los efectos de las imágenes y de los productos culturales de la animación y la realidad virtual en los procesos cognitivos. En el contexto de la educación, considera que el consumo de imágenes y los productos de entretenimiento, en términos de una relación ilusoria y contemplativa entre los fans e ídolos, es capaz de interferir con las habilidades críticas y valorativas de la mente.

Palabras clave: Hiperrealidad, espectáculo, cultura, cosmovisión.

\section{Resumo}

Este artigo trata com os conceitos de realidade e imaginário no contexto do desenvolvimento das tecnologias da comunicação e da virtualidade. A partir de pressuposições da teoria crítica da cultura de massa e do espetáculo, analisa os efeitos das imagens e dos produtos culturais do entretenimento e da realidade virtual sobre os processos cognitivos. No contexto da educação, considera o consumo das imagens e dos produtos do entretenimento em termos de uma relação ilusória e contemplativa entre fãs e ídolos capaz de interferir nas habilidades críticas e valorativas da mente.

Palabras llave: Hiper-realidade, entretenimento, cultura, visão de mundo.

\section{Abstract}

This article deals with the concepts of reality and imagination in the development of communication technology and virtuality. From assumptions of critical theory of mass culture and spectacle, analyzes the effects of images and cultural products of the entertainment and virtual reality on cognitive processes. In the context of education, considers the consumption of images and entertainment products in terms of a relationship between illusory and contemplative fans and idols able to interfere with the critical skills and evaluative mind.

Key words: Hyperreality, entertainment, culture, worldview. 


\section{Introdução -}

Os comportamentos adictos em relação ao consumo audiovisual e à hiper-realidade desafiam o senso comum a pesquisa. Há pessoas que passam dezenas de horas na frente de uma tela de computador, mesmo sem se alimentar e descansar. Outros trocam o ambiente agradável de uma praia ou em meio à natureza para navegar horas a fio na internet. Ainda há os que preferem as aventuras da ficção nas telas do cinema e da televisão a aventuras reais no mundo concreto da vida. Torcedores e fãs gastam tempo e dinheiro e mesmo a vida para acompanhar, seguir e imitar seus ídolos.

Em que consiste essa força tão atrativa do mundo virtual reproduzido nas comunicações audiovisuais capazes de seduzir e prender a atenção de milhões de pessoas? Por que as pessoas trocam experiências reais e factuais pela aventura do ciberespaço e das produções do mundo do entretenimento? Numa perspectiva educacional, que efeitos essa revolução imagética e contemplativa que gerou uma compulsão pelo consumo de espetáculos pode provocar no processo de formação e desenvolvimento do pensamento e do juízo ético?

Este artigo tem o objetivo de analisar a compulsão pelo consumo audiovisual no contexto da revolução das tecnologias da comunicação a partir de uma perspectiva educacional confessional. Para tanto, faz uso de alguns conceitos das teorias críticas da cultura de massa e da teoria do espetáculo.

\section{Conceitos -}

Para efeito de delimitação, alguns conceitos básicos devem ser definidos. O que é realidade, imaginário e tecnologia? Neste artigo, a ideia de realidade tem que ver com o mundo concreto da vida física e social no qual se desenvolve a consciência individual. Esta realidade concreta é submissa às leis da física, do tempo e do espaço. No aspecto moral e ético, a vida neste mundo é sujeita às restrições das leis morais e da responsabilidade social.

Por sua vez, imaginário se relaciona ao mundo das imagens da mente construídas pelos processos de abstração e imaginação (ver Durand, 1997). Nesse sentido, pode-se dizer que o imaginário é o espelho da fantasia, do desejo, da aspiração e dos sonhos. Esse domínio é independente de quaisquer leis ou restrições, já que a mente no processo imaginativo não conhece limites nem restrições. Não há interdições no mundo do imaginário. Ele toma expressão através de diversas atividades, mas especialmente na literatura, no cinema, novelas e no ciberespaço; as artes em geral. Neste artigo, o foco não está sobre 
a arte em si mesma, mas especificamente na cultura do entretenimento no contexto da cultura de massa e do ciberespaço ou mundo virtual.

E quanto à tecnologia? Este artigo não está interessado nas diversas tecnologias desenvolvidas para ajustar a vida humana ao mundo da natureza, em busca de sobrevivência, conforto e desenvolvimento. Mas nas tecnologias da comunicação que exploram o mundo das imagens e fantasias da mente e na onipresente cultura do entretenimento.

Embora essas tecnologias possam ser consideradas apenas como um meio neutro para a exploração e colonização do imaginário, em muitas análises, inclusive cinematográficas, elas têm sido retratadas como instrumentos inteligentes, capazes de seduzir, prender e dominar. Essas metáforas criadas especialmente pelo cinema, ao retratar as relações do homem com as máquinas, também sugerem a capacidade das tecnologias mesmo em alterar a constituição da mente e dos processos cognitivos dos receptores.

Nesse sentido, é memorável o filme Tempos Modernos, de 1936, do cineasta britânico Charles Chaplin, que empreendia uma crítica da primeira revolução industrial, no contexto do início do século 20. Nas experiências do personagem Charlie, as máquinas foram vistas ou representadas como onipresentes, imensas e capazes de pressionar o homem e alterar a própria vida e a realidade. No contexto do final do século 20 , na segunda revolução tecnológica, com o desenvolvimento dos computadores e das inteligências artificiais, as máquinas foram representadas em $O$ Exterminador do Futuro, de 1984, do cineasta canadense James Cameron, como organismos vivos, inteligentes e extremamente fortes. Na metáfora de Cameron, o ser humano deste momento histórico está acuado, dominado e rendido ao poder das tecnologias, capazes de impor uma verdadeira revolução e um domínio sobre a Terra.

Em Matrix, de 1999, os irmãos Andrew Paul Wachowski e Lana Wachowski pretenderam criar uma metáfora ainda mais aprofundada na análise do domínio e da onipresença das tecnologias, refletindo seu poder em termos da criação de uma segunda realidade: o mundo virtual, no qual as tecnologias possibilitaram de fato as pessoas adentrarem a uma segunda/outra dimensão da vida.

Essa realidade paralela, virtual e imaginária, de fato, ganhou vida e dimensão com o desenvolvimento mais recente das tecnologias da comunicação. Como representado em Matrix e outros, o imaginário, "o mundo dos sonhos", foi transformado na "hiper-realidade", uma dimensão fictícia, visual, irreal e tecnológica em que tudo existe num estado de perfeição e intensidade. Os 
recursos tecnológicos de reprodução e exploração do mundo do imaginário permitiram a criação de uma realidade à parte, a qual se apresenta como a própria libertação dos limites e das restrições do mundo real e concreto da vida. Em A República, livro VII, o filósofo grego Platão considerou a vida real e concreta do mundo físico como apenas uma representação, que se constituía numa prisão para a alma, e viu a fuga por meio do pensamento como a libertação almejada. Retomando Platão, a hiper-realidade se apresenta como o mundo encantado no qual seres abstratos, libertados do mundo concreto, desfrutam a verdadeira dimensão da existência, onde, contudo, nada existe senão potencialmente, ou imaginariamente.

Por sua vez, a realidade e o mundo concreto da vida, diante da exploração e colonização do imaginário, com imagens e sons aperfeiçoados à exaustão, tornou-se o "deserto do real", onde a vida não passa de uma prisão, sem atrativos, depois que o indivíduo conheceu o encantamento do mundo da hiper-realidade, através das tecnologias.

O transporte para o mundo do imaginário, intensificado e explorado à exaustão pelas novas tecnologias, tornou-se compulsivo e dominante. Os diversos aparelhos que possibilitam o transporte para a hiper-realidade transformaram-se em bens supremos, objetos de um aperfeiçoamento constante que garanta mais rapidez e vivacidade nas experiências virtuais. Computadores, tabletes e telefones celulares dos mais diferentes modelos passaram a fazer parte do corpo, como próteses indispensáveis, porque são os meios de fuga instantânea para a dimensão da hiper-realidade.

Por que se deveria reconhecer ou atribuir tanto poder às tecnologias digitais em sua capacidade de reprodução e exploração do imaginário? Podese dizer que as tecnologias digitais permitiram dar vida própria às imagens mentais. Além disso, elas permitiram reproduzir as fantasias do imaginário como o modelo mais elevado da realidade, atribuindo-lhes um status de realidade suprema, a exemplo da metafísica de Platão. Além disso, elas possibilitam a conexão imediata ao mundo do imaginário, garantindo que entre o indivíduo e a vida encantada de um mundo intenso e hiper-real já nenhum obstáculo mais pode existir.

O imaginário é reproduzido e explorado nos mais diversos produtos do mundo do entretenimento, entre eles, novelas, filmes, contos, jogos, campeonatos, festivais e mesmo alguns cultos religiosos.

Nesses produtos, as aspirações e fantasias da mente humana são vivenciadas ou realizadas pelos personagens do espetáculo, os quais foram alçados ao status de deuses. Artistas, atletas, cantores, humoristas, modelos 
e apresentadores são os novos "olimpianos" (Morrin, 1989) que compõem o "monte Olimpo" da realidade virtual. No mundo do espetáculo ou na hiperrealidade, em que tudo é reproduzido tecnologicamente para ser superior à realidade, esses ídolos "realizam" as mais diversas fantasias arquetípicas do imaginário. Nesse jogo, eles permitem ao telespectador, fã ou torcedor realizar ele próprio suas fantasias, de forma virtual e ilusória. Entre os fãs, torcedores, expectadores e seguidores, de um lado, e os "olimpianos", ídolos e artistas, do outro, ocorre de fato uma relação em que os primeiros têm a sensação de que "realizam" ainda que virtualmente suas aspirações e fantasias, impossíveis no mundo real e concreto da vida.

Devido à onipresença e predominância da hiper-realidade reproduzida e explorada pelas novas tecnologias e de seu elevado poder de sedução, é preciso considerar os efeitos e implicações do consumo generalizado das mesmas. De que forma pode tanto o consumo de espetáculos da cultura de massa quanto a alienação ou fuga constante para a hiper-realidade afetar a mente e os processos de aprendizagem e de pensamento? Como elas podem influenciar os mecanismos de juízo e valoração tão necessários à vida em sociedade e à educação?

\section{Espírito crítico -}

Uma primeira implicação do consumo de espetáculos e da experiências com a hiper-realidade tem que ver com a habilidade de criticar e julgar. Max Horkheimer e Theodor Adorno, dois pensadores da chamada Escola de Frankfurt, denunciaram os produtos do entretenimento, no contexto da indústria cultural, como capazes de "vetar", de fato, a "atividade intelectual do espectador", devido à demanda exacerbada de percepção e observação para o registro das imagens e dos fatos fragmentários (Adorno \& Horkheimer, 1985, p. 119). Para eles, a exploração das fantasias do imaginário confirma a alegação de Alexis de Tocqueville de que, "sob o monopólio privado da cultura", sucede que "a tirania deixa livre o corpo e investe diretamente sobre a alma" (ibid, p. 125). Os dois frankfurtianos acrescentaram ainda que a exploração da alma ou da mente se dá pela exploração da função do "prazer" ou da sensação, própria dos espetáculos simbólicos, nos quais predominam as "associações habituais", sendo que "toda ligação lógica que pressuponha um esforço intelectual é escrupulosamente evitada" (ibid, p. 128).

A proposição de que o consumo audiovisual do mundo do espetáculo implica limitação do discernimento e da consciência crítica foi desdobrada 
por Herbert Marcuse. No contexto do aperfeiçoamento da indústria cultural, baseado nos Estados Unidos, Marcuse considerou que o consumo dos meios audiovisuais permeados de estímulos sensoriais provoca um enfraquecimento do "pensamento abstrato e especulativo", condição em que "o princípio do prazer absorve o princípio da realidade" (Marcuse, 1973, p. 17, 82).

O pensador e ensaísta francês Guy Ernest Debord, considerado autor de uma teoria do mundo do espetáculo, propôs que o espetáculo e as imagens tecnologicamente produzidos interferem na capacidade do indivíduo de ver e interpretar criticamente o mundo. Para ele, a obstrução do pensamento e a estimulação dos sentidos, no contexto da exploração do imaginário, chegam a tal ponto que o consumidor de espetáculos prefere a representação à realidade e considera a ilusão como algo sagrado e a verdade como profana (Debord, 1997, p. 15). No espetáculo, as imagens e os ídolos se tornam seres reais e motivações eficientes de um comportamento hipnótico, o que projeta o espetáculo não apenas como um conjunto de imagens, mas "uma relação entre pessoas, mediada pelas imagens" (ibid, p. 14, 18). Essa relação leva o indivíduo a uma dispersão de suas energias criativas e à ilusão de realizar virtualmente suas aspirações, embora sua ação seja somente a de um passivo consumidor de imagens. "Quanto mais ele contempla, menos vive; quanto mais aceita reconhecer-se nas imagens dominantes da necessidade, menos compreende sua própria existência e seu próprio desejo" (ibid, p. 24). Assim, Debord registrou "a falsificação do mundo através da mídia e a substituição das vivências diretas dos homens pela condição de espectador, pelo consumo passivo de imagens" (Fridman, 2000, p. 24).

Devido ao processo hipnótico resultante do consumo de imagens, o historiador americano Daniel Boorstin diz que a revolução tecnológica e a decorrente exploração do imaginário para o entretenimento produzem um novo tipo de pensamento, o "imagético". Isso ocorre, segundo ele, em detrimento do que qualificou como "pensamento ideal", ou seja, "pensar em termos de alguma ideia ou valor ao qual se possa aspirar" (Boorstin, 1987, p. 177-178), o que substitui “a aspiração pela gratificação" (Gabler, 2000, p. 57).

Segundo a visão de Boorstin, o pensamento imagético desloca o pensamento ideal, por causa da ascensão do critério estético, tão explorado pelas tecnologias de reprodução das imagens. O pensamento imagético leva as pessoas a escolherem seus governantes da mesma forma que escolhem automóveis, roupas, sapatos, casas, móveis, pelos critérios e limites da imagem estética (Boorstin, 1987, p. 188). 
A hiper-realidade, portanto, seja a da cultura de massa ou da virtualidade reproduzida pelas tecnologias digitais, apresenta-se como uma nova cultura em que as vivências diretas e concretas do indivíduo são substituídas por experiências contemplativas e alienadoras.

\section{Significação -}

Além do processo de alienação do mundo concreto e da vida real, o consumo de imagens e as experiências com a hiper-realidade também são vistos como empecilhos ao processo de dar sentido e explicar o mundo representado nessas imagens, por parte do indivíduo. Já na década de 1930, o ensaísta Walter Benjamin alertava para o fim próximo da "narração", como o desaparecimento de uma faculdade indispensável, a de estabelecer troca de experiências (Benjamin, 1983, p. 57). Da mesma forma que o carro, para usar a linguagem de McLuhan (2001), "estendeu" o alcance dos passos do ser humano, mas também atrofiou seus movimentos, a imagem midiatizada amplia a visão, mas atrofia a capacidade de analisar o que se vê e de contar histórias sobre essas coisas (Stephens, 1993, p. 640).

Discutindo a relação entre inteligência, pensamento abstrato e sintaxe, o cientista político italiano Giovanni Sartori, em Homo Videns, propõe que a cultura audiovisual das telas pode estar, de fato, mudando a natureza do homo sapiens, produzido pela cultura escrita, ao interferir em sua capacidade de abstração (Sartori, 2001, p. 10). Segundo ele, como a linguagem é um instrumento não só para o ser humano se comunicar, mas também para pensar, "é a passagem da civilização oral para a escrita que desenvolve a civilização" (ibid, p. 13); e, consequentemente, sem a tipografia também não haveria lluminismo (ibid, p. 18). O progresso científico e humano, resultante do lluminismo, segundo SARTORI, só foi possível graças ao desenvolvimento da "capacidade de abstração", que possibilita à mente processos intelectuais dedutivos e a criação de valores e conceitos ideais, que estão além das coisas visíveis, para serem alcançados. Ele argumenta que "o que nós vemos e percebemos concretamente não produz ideias, mas se insere nas ideias (ou conceitos) que o classificam e significam". É esse processo de dar significado e de pensar com ideias que a cultura audiovisual tende a atrofiar e trancar seu desenvolvimento (ibid, p. 33).

O historiador francês Henri-Jean Martín diz que é inevitável concluir que o acesso aos livros contribuiu para a estruturação da ordem social na era moderna (Martín, 1992, p. 27). A cultura do livro, segundo ele, criada pela 
imprensa, só podia ser "possuída" através de um processo de aprendizagem em que as aptidões mentais para ler são adquiridas aos poucos. O resultado dessa aprendizagem é "a habilidade de conectar e associar, a familiaridade com o idioma, a facilidade de expressão, a destreza em acompanhar um argumento, a compreensão de distinções refinadas, e por fim, uma maior confiança e aptidão para adquirir novos conhecimentos" (ibid). Nesse sentido, a cultura tipográfica ajusta a mente para o pensamento humanista, imbuído de valores humanos universais, oriundos de uma leitura linear e associativa da história.

Embora as novas tecnologias tenham facilitado o acesso rápido e quase generalizado aos conteúdos e imagens do mundo, o simples acesso a esses conteúdos não resulta necessariamente numa expansão da capacidade de pensar e entender o mundo e de reagir a ele. Pelo contrário, a habilidade de pensar, conectar e dar sentido às coisas pode estar sendo restringida, tanto pela multiplicidade de mensagens e imagens quanto pela superficialidade e pela estimulação da função do prazer vinculada a esse consumo midiático.

\section{Ética e moral -}

A experiência com o mundo das imagens reproduzidas tecnologicamente deve ser vista, no contexto da educação cristã confessional, à luz do grande conflito entre o bem e o mal, em que não apenas conceitos de civilização e inteligência estão envolvidos, mas também habilidades éticas e morais.

O filósofo político francês Jean-François Mattei analisa o favorecimento do juízo estético em detrimento do juízo ético e moral, resultante da leitura e consumo de imagens midiatizadas. No contexto da divulgação dos atentados terroristas de 11 de setembro de 2001, nos Estados Unidos, ele escreveu o artigo intitulado "A barbárie da inteligência, ou O ground zero do pensamento". Mattei (2002), considerou a avaliação do compositor Karlheinz Stockhausen, que qualificou a imagem do atentado como "a maior obra de arte jamais realizada", e do filósofo Jean Baudrillard, que o chamou de "o evento absoluto", com o qual "todos tínhamos sonhado", como evidências de um "apagamento progressivo do horizonte moral" na paisagem do pensamento contemporâneo. A realidade fotografada e mostrada segundo critérios estéticos e plásticos, segundo ele, gera o fenômeno do "silêncio do real" (Mattei, 2002, p. 11-13). O espetáculo, seja representando guerra e sofrimento ou as fantasias da mente, engessa o pensamento e silencia o efeito de realidade.

Jacques Aumont, pesquisador de cinema em Sorbonne, afirma que a produção da imagem espetacular segue sempre um critério estético, pois "é 
destinada a agradar seu espectador e oferecer-lhe sensações", e o tipo de juízo a que se empenha o consumidor de imagem é dessa mesma natureza (Aumont, 1993, p. 80). Mattei conclui que, no consumo de imagens, o "juízo estético faz-se pouco a pouco substituto do juízo moral", portanto, "a realidade da violência é um espetáculo a que assistimos e que devemos interpretar em termos de ficção", mesmo se os mortos sejam bastante reais (Mattei, 2002, p. 13).

Aumont diz que o "consumo de imagens não se realiza sem prazer". Essa lógica das imagens espetaculares se deve ao fato de a imagem em geral ser vista como "uma espécie de extensão da imagem artística" e "o prazer que ela proporciona é da mesma ordem", inclusive a "imagem documentária" (Aumont1993, p. 312-313).

O crítico literário e sociólogo francês Roland Barthes analisa esse fenômeno como o que chama de efeito abortivo da denotação próprio da experiência audiovisual planejada para provocar sensações fortes, sejam de prazer ou medo. Partindo da hipótese de Piaget de que não há percepção ou entendimento sem categorização imediata, ele afirma que uma imagem ou conteúdo só pode ser percebido se for verbalizado. No processo de verbalização, o leitor precisa de um saber histórico a fim de que possa contextualizar e decodificar a comunicação. "Se a verbalização tarda, há desordem da percepção, interrogação, angústia do sujeito" (Barthes, 2002, p. 336). O êxtase ou choque de sensação pode interromper a significação da mensagem. Barthes considera como traumáticas ou sensacionais as imagens de incêndios, naufrágios, catástrofes, mortes violentas, colhidas "ao vivo", as que acionam forte sensação, e que são as mais comuns nas telas. Segundo ele, nenhum valor, nenhum saber e "nenhuma categorização verbal pode ter domínio sobre o processo institucional da significação" da fotografia traumática. O efeito de saber é "inversamente proporcional a seu efeito traumático" (ibid, p. 337).

O predomínio de imagens e dos conteúdos midiáticos destinados a produzir sensações fortes ao lado da rapidez com que são trocados nas trelas dos aparelhos facilita o processo de geração de um êxtase mental. Esse fluxo interrompe o processo de significação dos conteúdos, atrasando ou mesmo abortando toda iniciativa de interpretação e significação.

\section{Compulsão -}

Uma quarta implicação do consumo de imagens espetaculares e das experiências com a hiper-realidade tem que ver com a dependência resultante das sensações fortes causadas pelas imagens e conteúdos reproduzidos 
tecnologicamente. A progressiva estimulação da sensação relaciona-se retroativamente com uma expectativa compulsiva ou extravagante, em que se desperta e fortalece na mente um desejo crescente por imagens e experiências cada vez mais sensacionais, fortes e imediatas, esperando-se sempre mais do que aquilo que existe ou que é próprio da realidade e da vida concreta.

Os pesquisadores Muniz Sodré e Raquel Paiva sugerem esse fenômeno em termos de uma compulsão de espiar o sensacional, uma compulsão que busca por algo mais sensacional cada vez mais. Para eles, o que efetivamente seduz o espectador de espetáculos é o ato de ver, de espiar, de satisfazer-se escopicamente. Assim, o que se poderia chamar de consumo audiovisual seria uma compulsão de espiar o mundo ou suas imagens, somente pela pulsão de olhar, independentemente dos conteúdos ou dos significados. "A mirada concentra-se sobre o chocante na televisão do mesmo modo que sobre o malabarista de feira pública ou sobre o acidente na beira da estrada" (Muniz e Paiva, 2002, p. 139). O sociólogo Zigmunt Bauman também trata da angústia dos indivíduos transformados em "colecionadores de experiências e sensações", impelidos à busca permanente de novos êxtases (citado por Fridman, 2000, p. 66).

A satisfação dessa expectativa requer que a "fantasia" seja transformada em algo mais real do que a "realidade" pode oferecer; e, para cumprir essa função, a tecnologia se aperfeiçoa progressivamente. Assim, a imagem ou a representação do mundo passa a ter "mais dignidade do que o original" e "os pseudo-eventos, por sua natureza, tendem a ser mais interessantes e mais atrativos do que os eventos espontâneos" (ibid, p. 47). Eventos, espetáculos e representações são planejados cuidadosamente a fim de causar impacto.

O escritor italiano Umberto Eco analisa as cidades artificiais americanas, feitas para imitar a realidade, como reinos da fantasia e do imaginário. Essas cidades, pelo elevado nível de aperfeiçoamento do real, criam a ideia de um "Falso Absoluto". "Disneylândia nos diz que a técnica pode nos dar mais realidade que a natureza" (Eco, 1984, p. 56). Essa montagem espetacular da realidade cria ainda a persuasão de que a imitação atingiu "o próprio auge e que, daqui para frente, a realidade lhe será sempre inferior" (ibid, p. 58).

A superioridade "aparente" da hiper-realidade e do mundo do espetáculo, possibilitada pela tecnologia, planta a ideia de que o mundo real não passa de uma prisão, e a liberdade consiste em alienar-se para a hiperrealidade. Essa ideia provoca uma inversão dos valores em que o real se torna enganoso e o virtual assume o status supremo. Assim, é retomado o erro de 


\section{Vanderlei Dorneles}

Platão que negava a realidade do mundo concreto criado por Deus em benefício da exaltação da dimensão abstrata e irreal. Esse conceito de Platão era um desdobramento de suas ideias sobre a natureza abstrata e metafísica da alma, que contraria a visão bíblico-judaica que concebe o ser humano como uma unidade física, mental e espiritual.

Atitudes -

Em vista da proposta da educação cristã confessional, que busca não apenas o desenvolvimento intelectual, mas também das habilidades de criticar, selecionar e julgar, uma postura crítica e proativa frente ao predomínio do consumo midiático e virtual é necessária e plenamente justificada. Os educadores devem reconhecer que, no contexto das mídias audiovisuais, é imenso o desafio de educar e formar um ser humano capaz de julgar de forma moral e ética e de pensar por si mesmo. É preciso tomar medidas preventivas a fim de levar os estudantes a uma relação crítica e independente com os meios de comunicação de modo geral e com a chamada hiper-realidade, em particular. Algumas dessas medidas sugeridas são esboçadas resumidamente a seguir. Cada uma delas pode ser melhor explicada e implementada segundo cada contexto.

Os educadores precisam minar as bases da confiança dos estudantes na hiper-realidade e no mundo das imagens e dos espetáculos. É preciso mostrar como as habilidades e competências tão necessárias ao sucesso pessoal, profissional e espiritual podem ser enfraquecidas pela exposição prolongada e pela postura passiva e consumista diante das telas em geral.

Educadores e professores de escolas confessionais cristãs também devem perceber e explicar como o desenvolvimento da tecnologia e da virtualidade se constitui num desdobramento do grande conflito entre o Cristo e Satanás, segundo a visão bíblica. Nessa perspectiva, o mundo do espetáculo e das imagens midiáticas, permeados de ídolos e deuses de plástico, se apresenta como uma forma de idolatria, um novo "monte Olimpo", com cujos deuses as pessoas desenvolvem relações de admiração, adoração e imitação, em transgressão dos mandamentos divinos.

Escolas e instituições religiosas precisam considerar circunstâncias e momentos em que a disponibilidade da conexão com o mundo virtual em qualquer de seus limites seja prejudicial ao bom desempenho das atividades educativas. Constatada a situação, medidas para bloquear o contato com o mundo das imagens e da virtualidade devem ser tomadas para benefício do 
processo educativo e formativo. Em sala de aula, os professores não deveriam ser expostos a uma concorrência desigual com os ídolos e as imagens do mundo do espetáculo e da virtualidade.

Além disso, é preciso planejar e manter atividades reais de relacionamento, estudo e trabalho que sejam valorizadas acima das atividades de relacionamento e consumo virtual.

Vanderlei Dorneles Casa Publicadora Brasileira email: van.dorneles@cpb.com.br 


\section{Vanderlei Dorneles}

\section{Referencias}

Adorno, T., Horkheimer, M. (1985). Dialética do Esclarecimento. Fragmentos Filosóficos. Rio de Janeiro: Jorge Zahar.

Aumont, J. (1993). A Imagem. Campinas, SP: Papirus.

Barthes, R. (2002). "A mensagem fotográfica”. In LIMA, Luiz Costa (org.). Teoria da Cultura de

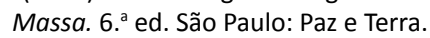

Benjamin, W. (1983). “O narrador”. In Textos Escolhidos. Os Pensadores. São Paulo: Abril.

Boorstin, D. (1987). The Image: A Guide to Pseudo-events in America. Nova York: Atheneum.

Debord, G. (1997). A Sociedade do Espetáculo. Rio de Janeiro: Contraponto.

Durand, G. (1997). As Estruturas Antropológicas do Imaginário. São Paulo: Martins Fontes.

Eco, H. (1984). Viagem na Irrealidade Cotidiana. Rio de Janeiro: Nova Fronteira.

Fridman, L. (2000). Vertigens Pós-modernas. Rio de Janeiro: Relume Dumará.

Gabler, N. (2000). Vida, o Filme: Como o Entretenimento Conquistou a Realidade. São Paulo: Cia das Letras.

Marcuse, H. (1973). A Ideologia da Sociedade Industrial: O Homem Unidimensional. 4. ${ }^{\text {a }}$ ed. Rio de Janeiro: Jorge Zahar.

Martín, H. (1992). "La imprenta”. In WILLIAMS, Raymond (org.). Historia de la comunicación. Barcelona: Bosch Comunicación.

McLuhan, M. (2001). Os Meios de Comunicação como Extensões do Homem. São Paulo: Cultrix.

Mattéi, J. (2002). “A barbárie da inteligência, ou O ground zero do pensamento". In ROSENFIELD, Denis L. e MATTÉl, Jean-François. O Terror. Rio de Janeiro: Jorge Zahar.

Morín, E. (1989). Cultura de Massa no Século XX. Vol. 1. Neurose. Rio de Janeiro: Forense Universitária.

Sartorí, G. (2001). Homo Videns: Televisão e Pós-pensamento. São Paulo: Edusc.

Sodré, M., Paiva, R. (2002). O Império do Grotesco. Rio de Janeiro: Mauad. 